\title{
Regimes adequados ao cumprimento das penas de reclusão e detenção - Estabelecimentos de prisão provisória
}

\author{
Basileu Garcia
}

A futura reforma penitenciária do Brasil há de assentar-se nas diretrizes já estabelecidas pelo moderno Código Penal de 1940. Os reformadores não poderão, ainda, perder de vista a excelente contribuição que resulta de um projeto de Código Penitenciário, que muito honra os nossos fóros de cultura. Redigiu-o a comissão constituida pelos snrs. Cândido Mendes de Almeida, Lemos Britto e Heitor Carrilho. Perpassando-lhe as páginas, somos agradavelmente impressionados pelo seu humanitarismo e pela preocupação de dar à pena, primacialmente, o escopo da regeneração do delinquente.

Evidentemente, esse projeto já não poderá, hoje, ser, de olhos fechados, transformado em lei, visto que entre a sua elaboração e a quadra atual medeiam quasi dez anos. Acontecimentos novos sobrevieram. As bases há anos esboçadas já não se harmonizam com o novo Código Penal. Cumpre lembrar que foi organizaro tendo $\mathrm{em}$ vista o projeto de Código Criminal então em estudos, da lavra de Virgílio de Sá Pereira.

As suas minuciosas disposições cogitam de variados estabelecimentos penitenciários, e a variedade de estabelecimentos penitenciários é requisito primordial de uma boa refórma. Não escapou à previsão dos seus elaboradores a necessária criação de sanatórios penais para presidiários tuberculosos. Sabe-se como o cárcere é propício à "peste 
branca"; como, especialmente nas cadeias não servidas de instalações adequadas, o contágio do terrivel "morbus" se manifesta facil e frequente. Uma boa organização penitenciária não se poderia descuidar de sanatórios penais para os presos portadores desse mal.

Referindo-se a penitenciárias, não se esqueceu o projeto de prover à criação de reformatórios, estabelecendo diferença entre os reformatórios propriamente ditos e as penitenciárias. Nos primeiros, o regime seria muito mais suave, dirigindo-se naturalmente a detentos mais susceptiveis de correção moral.

Adiantado se revela ainda o projeto no cuidado com que trata da organização e da preparação técnica do pessoal das instituições penitenciárias, ponto de grande relevância em qualquer reforma que se faça no assunto. Sem pessoal habilitado em perfeita técnica, escolhido através de rigorosos critérios de seleção moral e científica, fracassará todo esforço tendente à regeneração dos criminosos.

E' imprescindivel uma cuidadosa interpretação dos preceitos do Código Penal que dizem respeito ao cumprimento das penas de reclusão e detenção para, num panorâmico golpe de vista, prevermos o que serão as prisões do futuro no Brasil.

O nosso Código não adotou totalmente o sistema progressivo, dominante nas nações modernas. Em expressão feliz, o professor Roberto Lyra, que é um dos autores intelectuais do Código Penal de 1940, declara que o nosso Código seguiu um sistema progressivo, querendo assinalar ter admitido certas peculiaridades que o distanciam da forma tradicional do sistema aperfeiçoado pelo insigne Crofton.

\section{REFLEXOS DO MOVIMENTO ANTI-CELULAR}

A primeira peculiaridade que nos salta à vista, ao estudar o sistema progressivo brasileiro, é, por certo, o fato de que se caminha, no Brasil, para a exclusão, tanto quanto possivel, da cela ou célula. Deixou-se influenciar o legislador brasileiro de 1940 pelo movimento anti-celular de que 
é legenda a famosa frase de FERri, sempre repetida: "A cela é uma das aberrações do século XIX".

Quando FERri assim se manifestava, cuidava dos horrores da segregação celular absoluta, tal como a concebia o sistema de Filadélfia ou pensilvânico. Era o preso enclausurado como uma fera, quasi sem ar, sem luz, sem poder avistar outras criaturas humanas. Imaginava-se, com isso, subtraí-lo ao contato corruptor de companheiros mais pervertidos do que ele, ou tão pervertidos como ele, porque a convivência dos maus é sempre perniciosa. O que se conseguia, entretanto, era transformar o sentenciado numa criatura fora da substância humana, diferente dos homens comuns, não regenerado, mas gravemente prejudicado em sua saúde, do corpo e do espírito, pressuposto indispensavel do melhoramento moral.

Realmente, a cela, utilizada com esse rigor, constituia uma demonstração de impiedade, e bem se compreende o movimento filantrópico de reação que se lhe opôs. Já no sistema de Auburn passou a ser o que na verdade deve ser: o dormitório do recluso, em que ele, subtraído à promiscuidade nefasta, permanece apenas de noite segregado, após o labor em comum durante o dia. E assim continuou a ser a cela entendida no regime progressivo ou irlandês, com a restrição de que foi julgado necessário um inicial periodo, não pequeno, de isolamento absoluto. Crofron, entendendo ser excessivo o lapso inicial de segregação celular absoluta que esse sistema estabelecia para o sentenciado, reduziu-o a nove meses.

Observamos, no art. 30 do nosso Código Penal, que o isolamento celular absoluto se circunscreve ao lapso de três meses: "No periodo inicial do cumprimento da pena de reclusão, se o permitem as suas condições pessoais, fica o recluso tambem sujeito a isolamento durante o dia, por tempo não superior a três meses". Não é estabelecida, porem, essa segregação em carater de inflexivel obrigatoriedade. Há, no texto, uma ressalva benevolente, ao dispor-se que a providência dependerá das condições pessoais do sen- 
tenciado. Cabe à administração penitenciária dispensar do periodo de isolamento, em certos casos de reclusão, aqueles cujas condições pessoais sejam infensas à medida, que na verdade representa dura provação, ainda quando se evite como tal encará-la.

Com efeito, destina-se esse período de segregação absoluta à observação direta do sentenciado. No seu isolamento, é ele visitado pelos orgãos competentes da administração penitenciária, encarregados do seu minucioso conhecimento. Recebe assistência moral. E, através de todos esses cuidados, se colhem elementos para a determinação do conveniente tratamento penal que posteriormente lhe será imposto. E' natural que esse período seja restringido ao estritamente necessário para tais fins. Só se compreenderia a segregação absoluta com prazo fatal, se o seu objetivo fosse o castigo.

A esse respeito, é notavel o progresso representado pelo novo Código Penal, relativamente ao sistema do anterior, que preceituava perdurasse o periodo inicial de segregação absoluta por vezes até dois anos, em correspondência à duração da pena.

O isolamento celular é dispensado na pena de detenção. $\mathrm{E}$ esse é um dos traços característicos que distinguem as penas de reclusão e detenção, em nosso Código. De outro traço característico tratarei mais adiante, mas a ele acenarei desde logo: refere-se à qualidade do trabalho penitenciário. O trabalho do recluso não está subordinado à sua eventual preferência. Quanto à pena de detenção, permite-se que o detento, dentro das possibilidades materiais do estabelecimento, escolha o trabalho penal, contanto que tenha fim educativo.

Que representa um progresso a restrição ao uso da cela, não há dúvida. O moderno direito penal foge cada vez mais à antiga preocupação expiatoria e punitiva. Independentemente, porem, de tal consideração, mesmo para aqueles que insistem em ver na pena a retribuição do mal pelo mal, ainda se justifica essa tendência a evitar a cela. O 
Código Penal italiano ainda muito tem em apreço o carater aflitivo da pena. Reiteradas manifestações nesse sentido encontramos nos relatórios ministeriais de Rocco, não só a propósito do Código Penal como acerca do Regulamento Penitenciário. Entretanto, pondera Rocco, o seguinte, ao justificar o reduzidíssimo emprego da cela no sistema inovado em seu país: "Acreditava-se que a solidão forçaria o homem à meditação e a um recolhimento quase místico, mas teve-se de reconhecer que ela reforçava as tendências antisociais do condenado, tornando mais penosa e mais dificil a sua readaptação à vida social".

Tambem na Bélgica se cogitou de excluir, quanto possivel, a cela, na grande reforma penitenciária realizada sob os auspícios do cientista VervaecK.

Observa-se no Código Penal brasileiro não haver mais a antiga referência, constante da legislação revogada, à: obrigatoriedade do silêncio a partir do segundo período de cumprimento da pena privativa de liberdade. O Código não recomenda o silêncio, nem expressamente o exclue. A omissão, todavia, nos leva a crer que o legislador considera a obrigatoriedade do silêncio como inconveniente ao processo de ressocialização do delinquente.

Em São Paulo, no regime da lei anterior, que determinava que o preso permanecesse em silêncio no trabalho em comum, não era cegamente obedecida a advertência legal. Tolerava-se, com bom senso, certa relatividade, deixando-se de exigir, do sentenciado, o silêncio absoluto, que poderia concorrer para prejudicar o tratamento penitenciário.

\section{AS PENITENCIARIAS AGRfCOLAS}

O que, entretanto, mais nos deve preocupar na análise dos novos textos, encarados como diretrizes para a futura reforma penitenciária, é a matéria da qualidade e variedade dos estabelecimentos convenientes ao cumprimento das penas privativas de liberdade. Procuremos interpretar o 
Código Penal, conhecer-lhe o espírito e ver quais devem ser, no futuro, as prisões no Brasil. E a nossa mente é, desde logo, levada a apreciar o vivíssimo debate que se trava acerca das penitenciárias agrícolas.

Muito se fala, em nosso país e no estrangeiro, de alguns anos a esta parte, acerca das virtudes das penitenciárias agrícolas. E a propósito se faz inevitavel e lógica remissão às vantagens do labor ao ar livre. O trabalho "all'aperto", segundo a expressão tradicional em ciência penitenciária, era um dos postulados fundamentais da Escola Positiva, uma das preocupações máximas de Ferri, que entendia, com toda razão, que o contato do delinquente com a natureza é benéfico à sua regeneração. Benéfico do ponto de vista moral, quando não o fosse (e o é realmente) do ponto de vista físico e fisiológico, dando solução a inúmeros problemas oriundos da confirmação de seres humanos dentro de muros que lhes tolhem a liberdade infinitamente mais do que é preciso.

Ora, não podemos desconhecer as virtudes das penitenciárias agrícolas. Já NoÉ AzEvedo, em magistral palestra, fez o histórico do notavel presídio de Witzwill, na Suiça, realizado pela pertinácia de Kellerhals, que o construiu sobre um pântano drenado pelo esforço dos reclusos. Modelar se tornou esse estabelecimento penitenciário, que se mantem com os próprios recursos, originários da diuturna faina dos sentenciados, tendo constituido sólido pecúlio, em palpavel prova da boa orientação econômica, alem da excelente orientação reeducativa, dos métodos alí praticados.

Esse exemplo frutificou no mundo todo. Os Estados Unidos copiaram Witzwill, edificando um presídio que até no nome se inspirou na penitenciária suiça: o "Indianawitzwill". A "State Farm Prison" tambem aplica o sistema suiço das colónias agrícolas. Em 1934, a "Revista Penal y Penitenciária", de Buenos Aires, publicava, acerca desse modelar estabelecimento presidiário, um relatório-reportagem do professor Anchorena. O ilustre catedrático de Direito Penal mostrava, com exuberância, o seu entusiasmo 
pelo que vira, no ano anterior, no presidio de Witzwill. Pois bem, em 1940, é o mesmo professor Anchorena quem pronuncia o discurso de inauguração da Colónia Penitenciária de Las Pampas, na Argentina, a primeira das construídas naquela republica, apesar de se tratar de um país intensivamente agrícola. Em Portugal notabilizou-se, entre - os presídios, a Colónia Penal Agrícola de Sintra, à qual se refere com elogios Arí dos Santos, no livro "Como nascem, como vivem e como morrem os criminosos". No Brasil, é para nós todos motivo de orgulho o surto admiravel da Penitenciária Agrícola de Neves, em que se nota uma vida de relativa liberdade, tanto quanto é possivel permitir-se a homens que devem cumprir uma pena de privação da liberdade. E em São Paulo, onde notaveis iniciativas em matéria penitenciária se vêm verificando, graças aos esforços do Sr. Secretário da Segurança e diretor geral efetivo da Penitenciária, dr. Accácio Noguerra, tambem possuimos hoje a Penitenciária Agrícola de Taubaté, que se destina ao cumprimento do terceiro estágio da pena, constituindo, portanto, um prolongamento da Penitenciária Central, da Capital.

\section{NECESSIDADE DAS PRISÓES FORTES}

Essa direção ao campo é acertada. Não se podem contestar as virtudes do trabalho ao ar livre, como processo de regeneração do delinquente. Não nos enlevemos, porem, excessivamente, pelas seduções dessa modalidade de estabelecimentos penitenciários, tão excessivamente que nos esqueçamos da necessidade das prisões fortes, que devem ser mantidas, tambem, para o cumprimento das penas privativas de liberdade. Devem estas começar pelo aprisionamento nas sólidas construções presidiárias fechadas, em que seja possivel a observação imediata e meticulosa do delinquente, num contato mais direto e mais íntimo com os orgãos competentes, para os estudos técnicos e científicos. Nem se poderia, desde logo, confiar, levianamente, em indivíduos que se não conhecem, dando-lhes, no trabalho rural, 
a facil possibilidade de fuga, que desmoralizaria inteiramente a organização repressiva.

O próprio Crofton, ao aperfeiçoar o sistema irlandês, colocou a penitenciária agrícola numa determinada fase do processo regenerador do delinquente. Entendia que no mínimo por seis meses todo preso devcria ser encaminhado à faina rural, mas isso depois de haver cumprido parte da pena em penitenciária industrial. E recentemente, em artigo publicado na "Rivista di Diritto Penitenziario", o penitenciarista Dvorzak acentuava que o trabalho agrícola não deve ser concedido a todo e qualquer sentenciado, mas como um prêmio a seu esforço no sentido de obter o aperfeiçoamento moral.

Todos os grandes estabelecimenios agrícolas do mundo - 'e isso é capital para bem nos orientarmos - mantêm secções industriais. Assim é em Witzwill, onde tudo se fabrica de que têm necessidade os reclusos: camas de ferro, moveis, vestuário, etc.. Antes de screm encaminhados ao trabalho "all'aperto", são os sentenciados observados cuidadosamente, durante tempo mais ou menos prolongado, na labuta industrial a que se dedicam.

E mesmo Neves não é exclusivamente um presídio agrícola. $\mathrm{Na}$ "Revista Forense" foi publicado um artigo do pranteado desembargador paranaense Hugo Simas, relativo à visita que teve oportunidade de fazer à Penitenciária de Neves. Alude, com fervorosa admiração, àquela semi-liberdade em que vivem os sentenciados no trabalho ao ar livre.

A vigilância é realizada por presidiários que se confundem com os companheiros, dispensando-se a presença de funcionários. Duas vezes por dia um caminhão transporta a Belo Horizonte (Neves se encontra a quarenta quilómetros da Capital mineira), produtos agrícolas do estabelecimento, e traz de Belo Horizonte os suprimentos necessários. Esse transporte é feito pelos sentenciados. Mas Neves tambem possue prisões fortes e oficinas mecânicas, em que são empregados, nos primeiros tempos da pena, os sentenciados que para ali vão ter. 


\section{CONJUGAÇAO DE ESFORÇOS}

Nas linhas mestras que nos nortearão em matéria penitenciária, é interessante o preceito do art. $29 \S 30^{\circ}$ do Có-

digo Penal: "As penas de reclusão $e$ de detenção impostas pela justiça de um Estado podem ser cumpridas em estabelecimentos de outro Estado ou da União". A possibilidade de conjugarem diversas unidades federativas os seus esforços para fundar instituições de execução da pena, que sirvam a todas, muito concorrerá para a solução do problema penitenciário em nosso país.

A reunião de diversos estabelecimentos num só lugar foi aventada na Itália, em cuja capital, de uns anos a esta parte, se organiza a Cidade Penitenciária. A Cidade Penitenciária de Roma, como foi projetada, conterá toda a variedade de estabelecimentos presidiários, desde os destinados à prisão provisória até os de cumprimento das penas privativas da liberdade, quer para homens, quer para mulheres, havendo evidentemente, como é essencial, a mais completa separação entre sentenciados do sexo masculino e do sexo feminino.

No Brasil não seria facilmente praticavel a criação de cidades penitenciárias para atender às necessidades de vários Estados, em matéria repressiva. A vastidão territorial seria, para isso, um obstáculo. Dificil seria, senão o próprio transporte do condenado, pelo menos a realização das visitas periódicas das pessoas amigas e da família, elemento que se não deve excluir ao objetivar-se a reintegração social do delinquente. Feita essa ressalva, deve-se reconhecer que o sistema de centralização é economicamente vantajoso, pois se tornam mais accessiveis as instalações técnicas custosas e possibilita-se mais estreito intercâmbio entre as administrações penitenciárias, o que é de real valia para o aperfeiçoamento dos métodos. 


\section{OS REFORMATORIOS}

Depois de haver declarado que, se o permitirem as suas condições pessoais, o preso ficará segregado na céla durante o tempo máximo de três meses, estipula no $\S 1 .^{\circ} 0$ art. 30 do Código Penal: "O recluso passará, posteriormente, a trabalhar em comum, dentro do estabelecimento, ou em obras ou serviços públicos, fóra dele". E prossegue o parágrafo imediato: - "O recluso de bom procedimento pode ser transferido para colónia penal ou estabelecimento similar". Não se diz "colónia penal agricola"; mas "colónia penal" é expressão que nos induz a pensar nas colónias agricolas, visto que colónias penais são quasi sempre as colónias agrícolas. Parece, portanto, que o nosso legislador cogitou da colónia penal agrícola como um terceiro periodo de cumprimento da pena privativa da liberdade.

Observe-se a alusão a "estabelecimento similar". Deixou aquí o legislador brasileiro margem de iniciativa para que outros tipos de estabelecimentos presidiários se construam em nosso país. Interessante experiência a fazer, não para o cumprimento de um só estágio da pena, e visando-se determinadas categorias de sentenciados, especialmente os condenados à pena de delenção, seria tentarmos o sistema dos reformatórios norte-americanos.

Em 1896, surgiu nos Estados Unidos o célebre reformatório de Elmira. À sua frente, encontrava-se, e alí permaneceu por 24 anos, o grande Brockway. Conseguiu ele verdadeiros milagres nesse instituto, depois imitado por outros numerosos estabelecimentos daquele país. Seriam princípios fundamentais da sua organização, em primeiro lugar, a rigorosa seleção dos sentenciados submetidos ao seu tratamento penal. Só deveriam ser recebidos os delinquentes primários, em relação aos quais houvesse fundada esperança de correção moral. Em segundo lugar, alí se aplicaria a pena indeterminada. Encaminhado para Elmira, o sentenciado só poderia sair do reformatório depois de demons- 
trada a sua regeneração. Havia, rcalmente, um limite (e por isso se deve dizer que a pena não era absolutamente indeterminada e sim relativamente indeterminada), fixado na duração máxima da pena, abstratamente cominada na lei para o crime praticado. Mas, sem falar nesse limite extremo da pena, estava ao alcance do recluso, pela persistência no bom procedimento, a obtenção da almejada liberdade. A sentença indeterminada produziu ótimos resultados.

O regime, em Elmira, não era, como se pode desprevenidamente supor, excessivamente mitigado e sentimental. Quando se fala em reformatório, imagina-se um estabelecimento em que a mansidão e a suavidade sejam as únicas normas. Não, Brockway teve ocasião de dizer que o sentimentalismo era como que uma viga podre em um edifício, pois - explicava - carcome as outras vigas e provoca a ruina. Tão severo era o diretor de Elmira e tantas vezes teve ocasião de empregar os castigos corporais, que, certa vez, sofreu rude campanha dos jornais de Nova York, e foi preciso que, para apaziguar os ânimos, uma lei declarasse que os castigos corporais eram necessários naquele reformatório, a juizo do seu diretor.

Não era, portanto, um regime de franca benevolência. Mas em Brockway havia um grande empreendedor. Ele era, como devem ser todos os administradores de prisões, um profundo conhecedor da natureza humana, provido de admiravel senso psicológico, de ụm poder de intuição que muito o auxiliava no revigoramento dos sentimentos morais embotados daqueles que tinha sob a sua providencial tutela.

Com esse cuidado voltado à seleção do pessoal penitenciário, do ponto de vista intelectual e moral, se devem organizar as nossas prisões.

Uma das características interessantes do sistema de Elmira era a sua militarização. Os reclusos constituiam um completo regimento, em que se efetuavam promoções e degradações à vista do público, para que cada vez mais se esti- 
mulasse o senso de dignidade dos que se haviam abastardado na prática de um crime.

No Brasil, bem poderiamos tentar o sistema dos reformatórios, restrição feita, como facilimente se compreenderá, à possibilidade do emprego dos castigos corporais, contra os quais decididamente me insurjo. O sistema desses reformatórios era, em última análise, o que se aplica à correção dos menores delinquentes. Por que não tentar, em relação a homens que delinquiram pela primeira vez, métodos cabiveis a menores que se estrearam no crime?

\section{O LIVRAMENTO CONDICIONAL}

A sentença indeterminada, nós rão a possuimos, em: suas formas típicas, como a definem os doutrinadores. Entretanto, a sentença penal, em nossu meio, não é rigidamente determinada, dada a aplicação que fazemos do instituto do livramento condicional. A frase de Garraud de que "o livramento condicional dá ao preso as chaves da prisão" é uma verdade no Brasil, cujo Código Penal estabelece que após o cumprimento de mais de metade da pena pode o recluso reconquistar condicicnalmente a liberdade.

O êxito da nossa futura organização penitenciária muito dependerá dos cuidados que dirijamos à execução desse instituto. Não deve o livramento condicional ser concedido automaticamente. $\mathrm{E}^{\prime}$ preciso que ele constitua realmente um prêmio à boa conduta. O atual Código já não se satisfaz, como acontecia com o anterior esiatuto, com sinais de regeneração. Peremptoriamente exige a demonstração de haver cessado a periculosidade do sentenciado. E' mister que os Conselhos Penitenciários, que, por expressa disposição de lei, devem sempre opinar acerca de cada pedido de livramento condicional, sejam providos dos mais amplos e eficazes meios de conhecimento da pessoa do sentenciado, para que só seja beneficiado com a medida legal aquele que realmente a mereça. 
São Paulo encontra-se, a esse respeito, na vanguarda. Existe em nossa Penitenciária o Instituto de Biotipologia Criminal.

O movimento científico para o conhecimento da pessoa do sentenciado nasceu com a iniciativa de Vervaeck, empreendida na Bélgica desde 1907. Alí começaram a aparecer os anexos psiquiátricos, as clínicas de estudos antropológicos, biológicos e psicológicos da pessoa do sentenciado. $\mathrm{E}$ depois espraiaram-se esses institutos para a Baviera, para a Prússia e foram ganhando terreno nas mais adiantadas nações do mundo.

O Brasil não permaneceu indiferente a esse movimento. A nossa Penitenciária organizou tambem o seu laboratório de Biotipologia, que, destinando-se a estudar o individuo criminoso, fornecerá ao Conselho Penitenciário muitos dos dados de que carece para continuar na individualização administrativa da pena, através da conveniente aplicação do instituto do livramento condicional.

Em três aspectos se desdobra a tarefa da individualização da pena. Individualiza-se a pena na fase legal ou jurídica, quando a lei a comina em maior ou menor intensidade para cada modalidade criminosa encarada em abstrato. Individualiza a pena o magistrado criminal, quando a impõe, tendo em atenção as condições peculiares do delinquente. Mas aí não deve parar a individualização da pena. Deve prosseguir no cárcere, através de constante observação do sentenciado. E deve prosseguir, ainda, no momento em que, através de um processo conciencioso de seleção, se distinguem e premeiam aqueles que merecem o livramento condicional.

Entendo mesmo que esse trabalho de observação da pessoa do sentenciado deve ainda continuar fora do cárcere, depois que lhe seja concedido o livramento condicional.

Nos Estados Unidos existem os fiscais da liberdade condicional, que, ao lado da ação protetora, de assistência, dos patronatos, seguem de perto a vida extra-carcerária daquele que, às vezes mal aparelhado para a liberdade, acaba de 
sair do cárcere. Não convem deixar o condicionalmente liberto sem qualquer fiscalização. Devemos procurar certificar-nos da maneira pela qual ele usufrue o benefício que lhe é concedido, para impedí-lo de voltar ao crime, para trazê-lo, se preciso, ao cumprimento integral da pena, se não se conduzir como bom cidadão na vida social. Nem esperemos que torne a delinquir. Impeçâmo-lo de fazê-lo, coibindo-lhe para isso as oportunidades, através da ação desses fiscais que eu prevejo convenientes à boa execução do livramento condicional.

\section{O TRABALHO PENAL}

Entre as diferenças fixadas na legislação brasileira acerca das penas de reclusão e detenção, está a de que o detento tem a faculdade de escolher, evidentemente segundo as possibilidades dos estabelecimentos penitenciários, o trabalho penal.

O trabalho é uma imperiosa necessidade no cárcere. Os ingleses têm um provérbio que judiciosamente informa: "a mente desocupada é a oficina do demônio". Para ser possivel a regeneração do delinquente é preciso que ele se entregue a uma ocupação util, que lhe constitua um meio de cura, impedindo-o de voltar aos seus antigos maus pensamentos, às suas diabólicas maquinações, e que lhe favoreça a obtenção de meios para viver honestamente depois que saia do cárcere. Na ociosidade, que é mãe de todos os vícios, está muita vez a razão dos crimes. E' quasi sempre a relutância a entregar-se a um trabalho honesto que a certos indivíduos cria o ambiente moral propício a delinquir. $O$ trabalho penal, visando a regeneração do delinquente, deve tambem colimar a sua ressocialização, no sentido de que lhe torne possivel mais tarde uma vida proveitosa à sociedade, como elemento util integrado à comunhão social.

Mas os presídios não devem ser um peso morto nos orçamentos do Estado. E' preciso que sejam compensadoras as ocupações do presidiário. Pela sua natureza e pela apti- 
dão que produza, deve o trabalho poder ser-lhe vantajoso de futuro, como arma eficaz de luta pela subsistência. Deve ainda proporcionar-lhe equitativa remuneração, com a qual paulatinamente se forme o seu pecúlio, disponivel e de reserva, segundo a técnica usual, adotada em nossa Penitenciária. Essas modestas economias servirão às suas necessidades imediatas e de sua família. E quando o presidiário reconquistar a liberdade, serão um elemento de probabilidade da sua vitória sobre as primeiras vicissitudes.

Cumpre, por outro lado, que o trabalho penal, sendo compensador, permita às prisões viverem por sí próprias. Os ingleses, dotados de muito senso prático, querem que as prisões se subordinem ao principio do "self-supporting". Com esse pressupösto, têm empregado sentenciados em grandiosas obras públicas, fazendo-os construir diques, portos, edifícios públicos, etc.. Nos Estados Unidos, tem sido praticado o sistema das prisões federais em forma de acampamento, graças ao qual importantes obras públicas têm sido realizadas.

O trabalho penal, na futura organização penitenciária do Brasil, atendendo, como deve atender, a esses alvitres da experiência penitenciária, terá ainda de atentar à distinção, que a lei estabelece, entre as penas de detenção e reclusão. Deve ser bastante variado, em suas modalidades, o trabalho penitenciário, para que bem se individualize o tratamento penal, que se realiza, na sua maior parte, através do exercício de sãs ocupações. E não só: tambem para que, na medida do possivel e como quer a lei, se faculte ao detento - o que sofre a pena de detenção - escolher o trabalho que lhe seja mais atraente e proveitoso.

\section{ASPECTOS DA PRISAO PROVISORIA}

A prisão provisória é a ante-câmara do cárcere definitivo. Poderá ser tambem a ante-câmara da liberdade, uma vez que, preventivamente preso, para fins processuais, pode ser inocente $o$ indiciado. 
E' esta mesmo uma das razões pelas quais tanto se combateu em todo o mundo o instituto da prisão preventiva. Eu a encaro, neste momento, "lato sensu", como sendo toda e qualquer prisão realizada antes de sentença condenatória transitada em julgado. $E^{\prime}$ evidente que, muitas vezes, a prisão preventiva representa grave injustiça, como limitação ao direito individual à liberdade. No interesse social, é o cidadão lesado nesse importante bem jurídico, que é a liberdade corpórea, porque se vai fazer a investigação de um crime e se receia a sua fuga ou que de outro modo perturbe a ação da justiça.

Ortolan, em frase sempre lembrada, acentuou que a prisão preventiva é uma fatal necessidade. E como necessidade, os processualistas se têm esforçado em restringi-la o máximo possivel, em circunscrevê-la a precisos limites.

Esses limites, ditados pela necessidade, devem ser observados não só na predeterminação dos casos excepcionais em que será permitido ao magistrado criminal decretar a prisão para fins processuais, como tambem através da maneira pela qual se deve ela executar. $O$ que significa que os estabelecimentos de prisão provisória, a que chamamos vulgarmente "cadeias públicas" e hoje, nas capitais, "casas de detenção", devem evitar todo rigor que não seja absolutamente imprescindivel à disciplina.

Sob esse princípio norteador se devem organizar as cassas de prisão provisória.

Convem chamar a atenção para a impropriedade atual do nome "casa de detenção", visto que a detenção é, no vigente direito penal brasileiro, uma pena, e tais estabelecimentos não se destinam essencialmente ao cumprimento de pena. A meu ver, poder-se-ia dar-lhes o nome que têm na Itália - prisões judiciárias; ou então: estabelecimentos de prisão provisória ou presídios provisórios, evitando-se, como quer que seja, o nome "casa de detenção", que dá idéia de instituto para o cumprimento da pena intitulada detenção.

Não é, porem, o nome o que mais importa. Não nos esqueçamos, nos regulamentos adequados a tais estabeleci- 
mentos, de evitar demasias de severidade, incompativeis com a sua destinação, como ficou frisado.

Interessante paralelo se encontra, num artigo publicado na "Revue de Droit Pénal e de Criminologie", entre o sistema da Bélgica e o da Itália. Na Itália - bem ao contrário das tendências verificadas naquele outro país - veemente reação se faz sentir contra o mundial liberalismo a propósito da execução da prisão preventiva, e medidas draconianas foram adotadas, as quais o ministro Rocco procura justificar em seu relatório que precede o Regulamento Penitenciário. Basta, de relance, salientar que o próprio advogado do preso, para avistar-se com o seu constituinte, precisa de autorização do juiz. A correspondência do indiciado deve ser submetida ao "visto" do magistrado à cuja disposição se encontra. E a lei nem sequer faz ressalva expressa, como seria razoavel fizesse, acerca do indispensavel direito que deve ter o advogado de corresponder-se, a todo e qualquer momento, por escrito, senão verbalmente, com o seu constituinte. Parece, dada a omissão, que a correspondência do advogado tambem não se livra do "visto" do magistrado.

O trabalho é imposto ao preso durante determinadas horas, que quase lhe tomam o dia todo. Se não lhe tomam o dia todo, é porque parte do tempo disponivel é aplicado na obrigatoriedade da frequência à escola, quando se trate de pessoa iletrada.

Dir-se-á que o trabalho é vantajoso, que a instrução é um benefício. Mas não é justo forçar a um e a outra indivíduos cuja culpabilidade não foi ainda comprovada legalmente, e que por isso não devem sofrer, como obrigação imposta, restrição alem das verdadeiramente imprescindiveis. $E^{\prime}$ de se não esquecer que todo esse tempo retirado à reduzida parcela de liberdade que sobra ao preso provisoriamente, ele não pode empregar no preparo da sua defesa, nos cuidados que deve votar ao processo-crime em que figura como protagonista principal. 
Quaisquer medidas que possam prejudicar o direito de defesa devem ser declaradas nocivas e imediatamente proscritas. A prisão provisória requer, sem dúvida, ordem. As restrições disciplinares são, às vezes, imprescindiveis, mas devem pautar-se por estrita moderação.

\section{O IDEAL DA REGENERAÇÃO}

O nosso Código Penal não se manifestou de forma peremptória, nem lhe cumpria fazê-lo, sobre este grave problema doutrinário: se a pena é um castigo, se a pena é principalmente ou exclusivamente um meio de regeneração. Isso não impede, entretanto, que o interpretemos de acordo com as suas diretrizes progressistas. A pena não deve ser encarada como um castigo. Por certo, aquele que a sofre como tal a receberá. Não tenhamos, porem, a preocupação de lha fazer sentir como um castigo, como a retribuição do mal pelo mal. Procuremos, na medida das nossas possibilidades, humanizá-la cada vez mais, na convicção de que assim prestaremos valioso serviço à coletividade.

$£$, em primeiro lugar, um dever de seres civilizados que vivem no século XX. É, alem do mais, salutar cautela de carater preventivo. Porque a cura daquele que delinquiu interessa muito mais à defesa coletiva do que a sua punição.

Assim, inspirêmo-nos sempre no ideal da regeneração do criminoso. Não desesperemos de conseguí-la. Alcemos como lema da nossa futura organização penitenciária aquele que LÉon BELYN, eminente pënitenciarista belga, quis colocar à frente dos institutos penitenciários do seu país: "Espoir, toujours!" Tenhamos a infatigavel esperança de conseguir a readatação social dos delinquentes. 